\title{
A Note on Tibetan Translation, Transliteration, and Citation
}

This text is based on taped interviews I conducted with Tibetans and materials translated from Tibetan. All quotations from Tibetan texts and interviews are my translations.

For the reader's convenience, Tibetan words in the text appear in a form approximating their pronunciation, followed in parentheses (the first time they are used) by the Wylie system's transliteration: for example, timsa (khrims sa). All Tibetan terms are indexed as well. (For more Tibetan terminology and Tibetan script, see French 1990a.)

References to Tibetan law codes throughout the text are based on my unpublished translation notebooks, cited by the following abbreviations with line numbers.

GP the Ganden Podrang Code of the Dalai Lamas notebook, I336 lines; translation of pp. 4I-95 of Tibetan Legal Materials I985

ND the Neudong Law Code notebook, 459 lines; translation of chap. 3 of Sangye, "Handwritten Law Code Notes"

Ts the Law Code of the Tsang Kings notebook, 696 lines; translation of chap. 5 of Sangye, "Handwritten Law Code Notes," and of "Khrims yig zhal lce bou gsum bzhugs so"

$\mathrm{Br}$ the Brown notebook, 723 lines (300-1023); translation of p. 25 to the end of Bod kyi khrims yig chen mo zhal lee bou drug gi'grel pa bzhugs so

BrCC the Brown notebook "Court Costs" section, I24 lines; translation of pp. I3I-35 of Tibetan Legal Materials i985 
the Green notebook, I69 pages; analysis and partial translation by Lobsang Shastri, with Rebecca French, of Library of Tibetan Works and Archives Documents

Note

LS the Law Stories notebook (cited by page number); translation of sections of Thubten Sangye's "Handwritten Law Code Notes" 
The Golden Yoke 


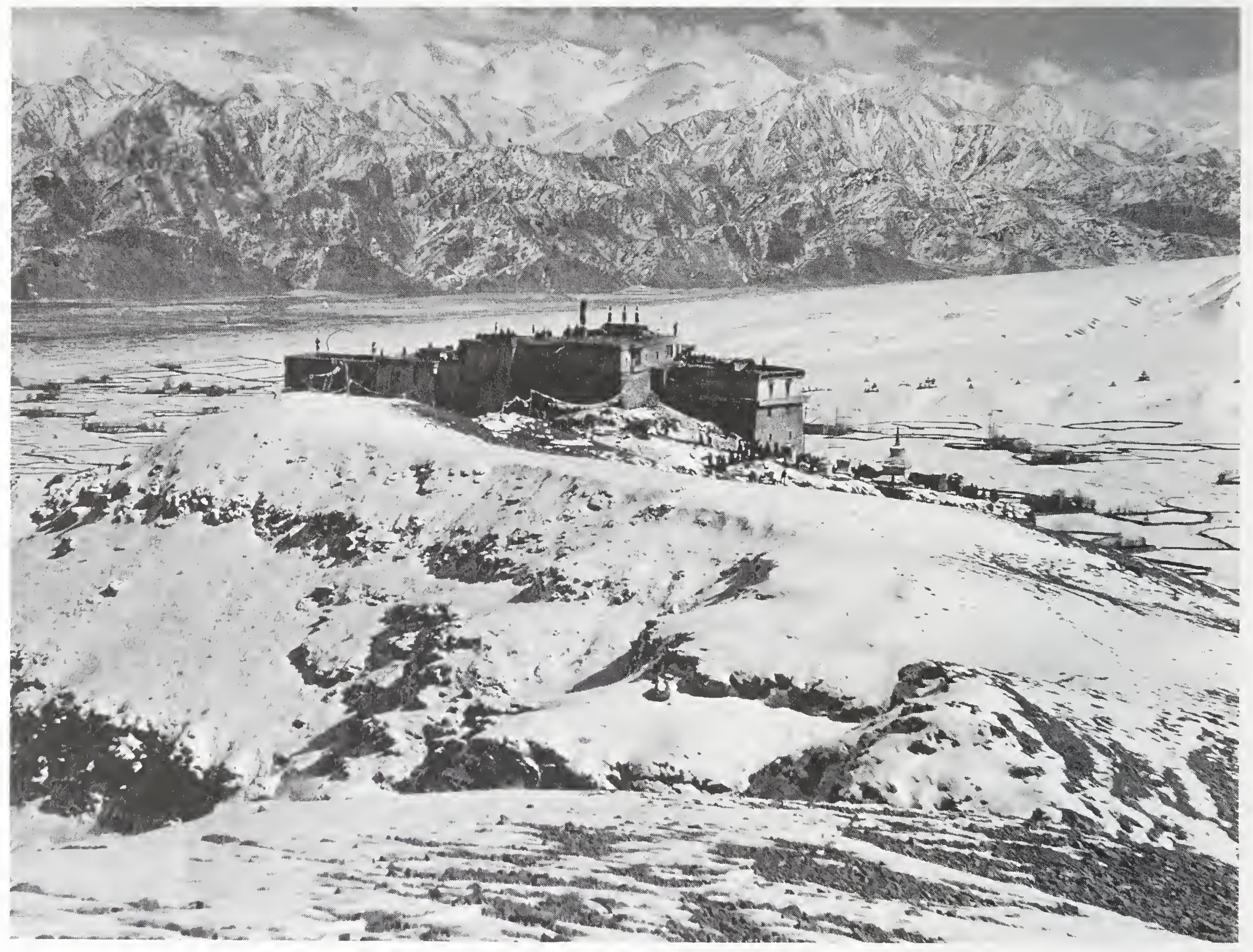

Plate 1. Mahro Monastery in western Tibet in the winter with estate lands below. 1976. (Syed Ali Shah, Leh, Ladakh) 